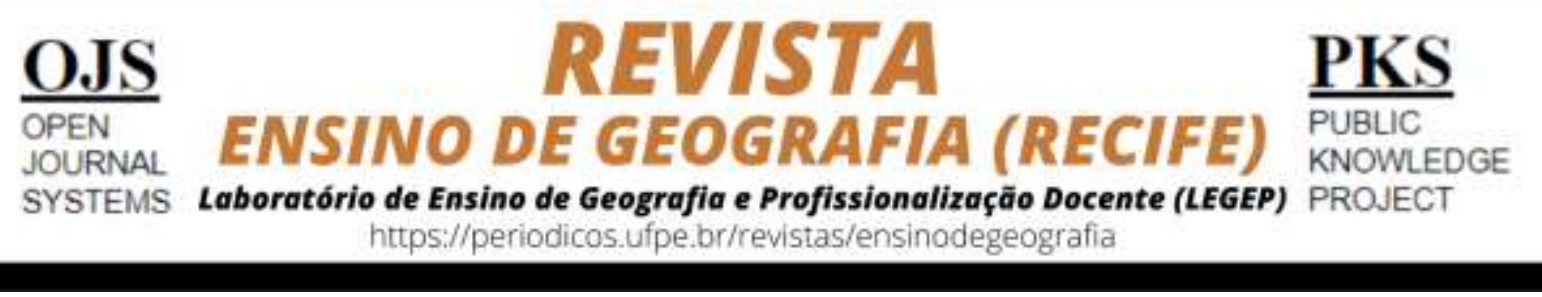

\title{
GEOGRAFIA NO ENSINO FUNDAMENTAL ANOS FINAIS: UMA ANÁLISE DO ENSINO PÚBLICO E PARTICULAR NO MUNICÍPIO DE PATOS-PB
}

\author{
Antônio Izidro Sobrinho ${ }^{1}$ \\ ${ }^{1}$ Mestre em Geografia pela Universidade Federal do Rio Grande do Norte. E-mail: antonioizidro58@gmail.com \\ ORCID iD: http://orcid.org/0000-0002-1357-4674
}

Artigo recebido em 27/03/2020 e aceito em 06/04/2020

\begin{abstract}
RESUMO
Os conhecimentos referentes à Geografia são bastante significativos para o entendimento do mundo atual, no entanto, percebe-se que estes têm tratamentos diferenciados quando se analisa a sua aplicabilidade nas redes pública e particular de ensino. Este artigo buscou identificar as dificuldades enfrentadas por professores de Geografia destas duas redes no tocante à transmissão dos conhecimentos geográficos. Para tal, foi realizada uma pesquisa exploratória por meio da aplicação de questionários em 10 instituições de ensino, sendo 5 públicas e 5 particulares. Percebeu-se que os professores de Geografia das escolas públicas enfrentam problemas estruturais como a falta de recursos didáticos e problemas de ordem social como a ausência da família no ambiente escolar. Neste sentido, diversos autores como Kaercher (2010) falam de uma mudança metodológica por parte dos professores, mas verifica-se que estes possuem outros desafios que apresentam maior dificuldade para serem superados. Conclui-se, portanto, que a disparidade entre a rede pública e privada no ensino fundamental no município de Patos - PB não se dá por incapacidade dos professores, mas sim, por uma escassez de recursos que auxiliam no desenvolvimento das aulas tornando-as mais dinâmicas e atrativas.
\end{abstract}

Palavras-chave: Ensino de Geografia; Redes de ensino; Ensino fundamental.

\section{GEOGRAPHY IN THE FINAL YEARS OF ELEMENTARY SCHOOL: AN ANALYSIS OF PUBLIC AND PRIVATE EDUCATION IN THE MUNICIPALITY OF PATOS-PB}

\begin{abstract}
The knowledge related to Geography is very significant for the understanding of the current world, however, it is seen that that this knowledge has different treatments when analyzing their applicability in public and private schools. This article sought to identify the difficulties faced by Geography teachers in these two school systems regarding the transmission of geographical knowledge. In order to this, an exploratory research was carried out through the application of questionnaires in 10 educational institutions, 5 public and 5 privates. It was noticed that Geography teachers from public school face structural problems such as the lack of didactic resources and social problems such as the absence of the family in the school environment. In this regard, several authors such as Kaercher (2010) talk about a methodological change on the part of teachers, but it turns out that they have other challenges that present greater difficulties to be overcome. It is concluded, therefore, that the disparity between the public and private schools in elementary education in the municipality of Patos-PB is not due to the incapacity of teachers, but rather due to a scarcity of resources that help in the development of classes, making them more dynamic and attractive.
\end{abstract}

Keywords: Geography teaching; Teaching networks; Elementary school. 


\section{INTRODUÇÃO}

Nos dias atuais, como disciplina escolar a Geografia "renasce" com o propósito de promover ao educando uma maior aprendizagem dos fenômenos que surgem da interação existente entre homem e meio. Este meio vale destacar, que perpassa por diversas escalas geográficas indo desde o local que o circunda até os lugares mais longínquos - o global.

Enquanto ciência a Geografia já passou por diversas reformulações nos seus métodos os quais pode-se destacar a Geografia tradicional e a Geografia crítica, por exemplo, que contribuíram para a formulação do seu objeto de estudo - o espaço geográfico - espaço este produzido justamente das diversas relações que se estabelecem entre o homem e o meio nas diferentes escalas citadas anteriormente.

O estudo da Geografia perpassa por diferentes escalas geográficas e sobre elas Callai (2000, p. 83) diz “[...] Ao estudar o espaço geográfico, a delimitação do mesmo é um passo necessário, pois o espaço é imenso, planetário, mundial. O que dele/nele estudar? [...]”. Assim, analisaremos o município de Patos - PB e nele estudaremos como se estabelece o ensino de Geografia no ensino fundamental.

Todos os documentos oficiais que orientam e regem a educação básica nacional a Geografia é retratada como sendo um componente curricular obrigatório. O documento mais atual é a Base Nacional Comum Curricular (BNCC) para o ensino fundamental aprovada em 2017 com meta para ser posta em prática em todo território nacional até este ano de 2020. Nela, a Geografia está no grupo das ciências humanas com a missão principal de promover o raciocínio geográfico formando um aluno crítico e consciente da sua atuação no espaço onde vive.

No entanto, apesar de possuirmos um documento que tenta homogeneizar a educação básica (neste caso, o ensino fundamental anos iniciais e finais, pois a base para o ensino médio ainda não foi aprovada) verifica-se que há uma grande discrepância na qualidade do ensino quando analisamos e comparamos as redes pública e particular.

Verifica-se, e isto é notório, que a rede particular apresenta um ensino de melhor qualidade (com raríssimas exceções) e com a abordagem da Geografia não parece ser diferente, uma vez que os professores de escolas públicas possuem maiores dificuldades em diversificar e dinamizar suas aulas. Diante dessa problemática, este artigo surge com o seguinte problema 
de pesquisa: Quais são os elementos de diferenciação na abordagem da Geografia em escolas públicas e particulares do município de Patos?

Para realização desta pesquisa buscou-se analisar os procedimentos metodológicos realizados e os recursos didáticos utilizados por professores de Geografia de escolas públicas e particulares do município de Patos - PB no tocante a abordagem dos conteúdos referentes ao componente curricular.

Diante disso, levantou-se as seguintes hipóteses: os professores das duas redes - pública e particular - possuem a mesma condição intelectual, uma vez que estes possuem o mesmo grau de escolaridade, ou seja, são graduados e pós-graduados na área em que atuam; na rede particular as aulas de Geografia são mais dinâmicas e atrativas aos alunos, pois os professores dispõem de maiores recursos didáticos.

Esta pesquisa justifica-se pela necessidade de dar respostas aos questionamentos realizados por parte da sociedade que enaltece o ensino promovido pela rede particular e despreza o ensino promovido na rede pública colocando em xeque a competencia dos professores sem sequer buscar entender os elementos constituintes da instituição, suas dificuldades, seus recursos, suas estruturas.

Para realização desta pesquisa foi feito um estudo de caso através da aplicação de questionário com questões semiestruturadas aplicados aos professores de Geografia de escolas públicas da rede municipal de ensino e escolas particulares do município de Patos, sertão paraibano. Para tanto, utilizou-se a pesquisa do tipo quali-quantitativa por meio da coleta de dados referentes ao questionário aplicado e através de uma análise subjetiva a respeito da problemática aplicada.

$\mathrm{O}$ artigo trata de modo geral e sucinta sobre o ensino de Geografia, suas evoluções e crises, mas de forma específica sobre as metodologias e os recursos disponíveis e utilizados pelos professores de Geografia de escolas públicas e particulares que têm na sua estrutura o ensino fundamental anos finais $-6^{\circ}$ ano $9^{\circ}$ anos.

\section{PROCEDIMENTOS METODOLÓGICOS}

Esta pesquisa foi realizada no município de Patos localizado no sertão paraibano. O estado da Paraíba foi regionalizado de acordo com o IBGE em 2017 em 4 Regiões Geográficas Intermediárias e em 15 Regiões Geográficas Imediatas e o município de Patos devido a sua importância econômica e privilegiada localização geográfica compõe uma região intermediária 
e uma região imediata que leva o seu nome. Isso demonstra a importância do município a nível estadual onde se enquadra na hierarquia urbana como um centro sub-regional.

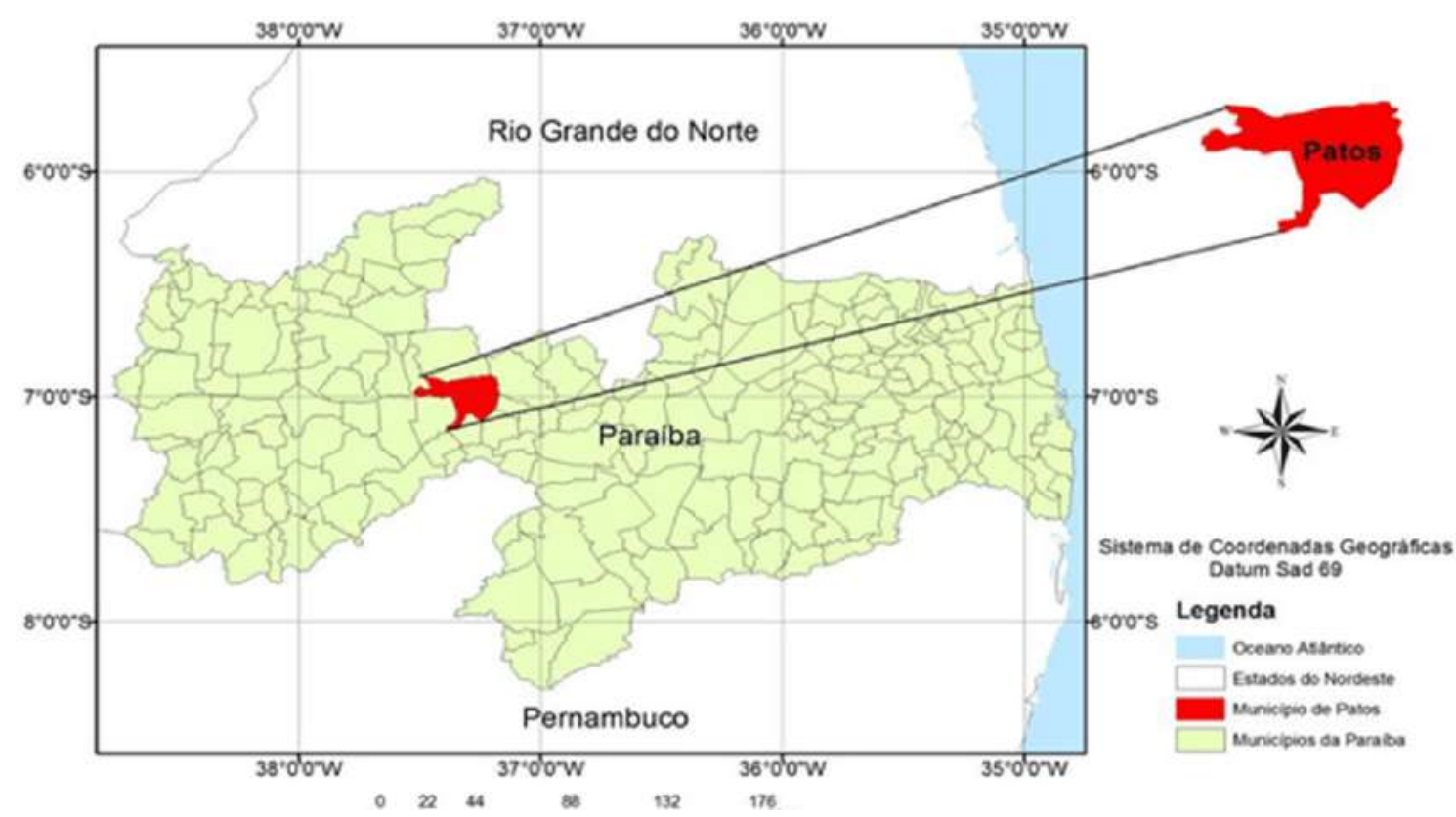

Figura 1: Localização do município de Patos no estado da Paraíba Disponível em: https://www.researchgate.net/figure/Figura-1-Mapa-geografico-do-Estado-da-Paraiba. Acesso em: 20 de março de 2020.

De acordo com estimativa demográfica realizada pelo IBGE (2019) o município tinha uma população estimada de 107.605 habitantes. De acordo com o portal QEdu da Fundação Lemann o município dispõe de 78 escolas públicas municipais (incluindo o ensino fundamental anos iniciais e finais) e 45 escolas particulares (incluindo toda a educação básica).

A seleção das escolas participantes desta pesquisa se deu de forma aleatória obedecendo ao seguinte critério: optou-se por realizar esta pesquisa nas cinco maiores escolas particulares (levando-se em consideração o número de alunos matriculados no ano letivo de 2020) e também por serem frequentemente destaques no cenário educacional municipal. Já as escolas públicas foram escolhidas geograficamente de forma estratégica, pois além de estarem entre as maiores da rede municipal estão localizadas em bairros longínquos e até mesmo em um distrito, o que nos dar uma maior amplitude da realidade local.

Diante disso, foram investigados os professores das seguintes instituições de ensino: 
Tabela 1: Escolas localizadas no Município de Patos-PB

\begin{tabular}{|c|c|}
\hline $\begin{array}{ll}\text { Públicas } \\
\end{array}$ & Particulares \\
\hline $\begin{array}{l}\text { - EMEF Dr. José Genuíno/Napoleão Nóbrega } \\
\text { (Bairro do Morro) }\end{array}$ & - Fera Colégio e Curso \\
\hline $\begin{array}{l}\text { - EMEF Aristides Hamad Timene } \\
\text { (Bairro Jardim Guanabara) }\end{array}$ & - Colégio Cristo Rei \\
\hline $\begin{array}{l}\text { - EMEF Dr. Firmino Ayres e Otto de Sousa Quinho } \\
\text { (Bairro do Jatobá) }\end{array}$ & - Vera Cruz \\
\hline $\begin{array}{l}\text { - EMEF Instituto Educacional Dr. Dionísio Costa } \\
\text { (Jardim Europa) }\end{array}$ & - Autêntico \\
\hline $\begin{array}{l}\text { - EMEF José Permínio Wanderley } \\
\text { (Distrito de Santa Gertrudes) }\end{array}$ & - Millenium \\
\hline
\end{tabular}

Fonte: Dados da pesquisa

Para isso, realizou-se uma pesquisa aplicada por meio da realização de questionários produzidos no Google online com questões objetivas e subjetivas que foram respondidos por professores das escolas que foram objetos desta investigação.

Gil (2006 apud ASSIS, 2009, p. 11) ao analisar os princípios da abordagem dialética diz que "quantidade e qualidade são características imanentes (inerentes) a todos os objetos e fenômenos e, estão inter-relacionados". Neste sentido, esta pesquisa se caracterizou de caráter descritivo por meio da utilização de livros, artigos científicos, dados de sites oficiais e exploratória (estudo de caso) onde foi feita uma abordagem quali-quantitativa por meio da análise dos dados obtidos em campo que foram disponibilizados em gráficos.

\section{FUNDAMENTAÇÃO TEÓRICA}

O ensino de Geografia nos documentos oficiais: breve análise

A sociedade atual passa por uma série de mudanças das mais variadas ordens: política, social, econômica, cultural, entre outras tantas. Estas mudanças têm gerado reflexos muito fortes no ambiente escolar, pois neste espaço as situações que ocorrem na sociedade se manifestam por meio de seus atores - os alunos. 
Para acompanhar tais alterações de modo que os alunos sejam protagonistas no espaço onde atuam e com o intuito de padronizar o ensino diante da grande diversidade brasileira foram estabelecidas algumas diretrizes que norteiam o ensino. Diretrizes estas que obedecem a uma hierarquia estando no topo os documentos elaborados pelo Ministério da Educação.

A educação brasileira é organizada oficialmente através de documentos que norteiam a sua prática no cotidiano escolar entre estes documentos estão: a Lei de Diretrizes e Bases da Educação Nacional (LDBEN, 9.394/96) criada em 20 de dezembro de 1996, os Parâmetros Curriculares Nacionais (PCNs) criados no final da década de 1990, a Base Nacional Comum Curricular (BNCC) e as Diretrizes Curriculares Nacionais (DCNs) e as Diretrizes Curriculares Estaduais (DCEs) e no ano de 2017, portanto, o documento mais novo e o que rege o ensino fundamental foi aprovado - a Base Nacional Comum Curricular (BNCC).

Essa é a grande contribuição da Geografia aos alunos da Educação Básica: desenvolver o pensamento espacial, estimulando o raciocínio geográfico para representar e interpretar o mundo em permanente transformação e relacionando componentes da sociedade e da natureza. Para tanto, é necessário assegurar a apropriação de conceitos para o domínio do conhecimento fatual (com destaque para os acontecimentos que podem ser observados e localizados no tempo e no espaço) e para o exercício da cidadania (BNCC, 2017, p. 360).

Sobre o ensino fundamental, nível de ensino analisado neste estudo, de acordo com o art. 32 inciso II da LDBEN (9.394/96) o ensino fundamental obrigatório, com duração de 9 (nove) anos terá por objetivo a formação básica do cidadão, mediante: "a compreensão do ambiente natural e social, do sistema político, da tecnologia, das artes e dos valores em que se fundamenta a sociedade" (BRASIL, 2017, p. 22).

De acordo com os PCNs (1997) a Geografia a ser trabalhada no ensino fundamental nos anos finais (de $6^{\circ}$ ao $9^{\circ}$ ano) deve promover por meio de suas diversas metodologias, o desenvolvimento integral do aluno como ser pensante, crítico, cidadão consciente e, portanto, conhecedor dos seus direitos e deveres dentro da sociedade onde vive.

No decorrer do Ensino Fundamental, os procedimentos de investigação em Ciências Humanas devem contribuir para que os alunos desenvolvam a capacidade de observação de diferentes indivíduos, situações e objetos que trazem à tona dinâmicas sociais em razão de sua própria natureza (tecnológica, morfológica, funcional). A Geografia e a História, ao longo dessa etapa, 
trabalham o reconhecimento do Eu e o sentimento de pertencimento dos alunos à vida da família e da comunidade (BNCC, 2017, p. 355).

Portanto, a BNCC (2017) propõe uma série de mudanças metodológicas no tocante à abordagem dos conteúdos relacionados ao ensino de Geografia e das demais ciências de tal modo que o aluno seja colocado como centro do processo de ensino-aprendizagem, como autor e produtor de conhecimento e não tão somente reprodutor do processo.

Evidente que muitas das orientações propostas pelo documento citado anteriormente já vinha sendo desenvolvida pela grande maioria dos professores de Geografia, no entanto, agora, teremos um elemento norteador que vai guiar e fundamentar nossas ações em sala de aula.

\section{RESULTADOS E DISCUSSÕES}

Geografia nas escolas públicas e particulares: similaridades e discrepâncias

Este estudo foi realizado através da aplicação de questionários com questões semiestruturadas as quais levaram em consideração um breve perfil pessoal dos entrevistados: gênero e faixa etária; perfil acadêmico - formação, pós-graduação; perfil profissional instituição onde exerce a docência, tempo de docência; mas de forma específica buscou-se entender as metodologias e os recursos utilizados por eles no tocante à abordagem dos conteúdos relacionados à Geografia.

Neste sentido, $60 \%$ dos entrevistados são do sexo masculino e $40 \%$ do sexo feminino o que demonstra certa igualdade entre os gêneros na docência de Geografia no município de Patos-PB. No tocante à faixa etária em que se encontra cada professor entrevistado obteve-se as seguintes informações: 
Gráfico 1: Faixa etária dos entrevistados

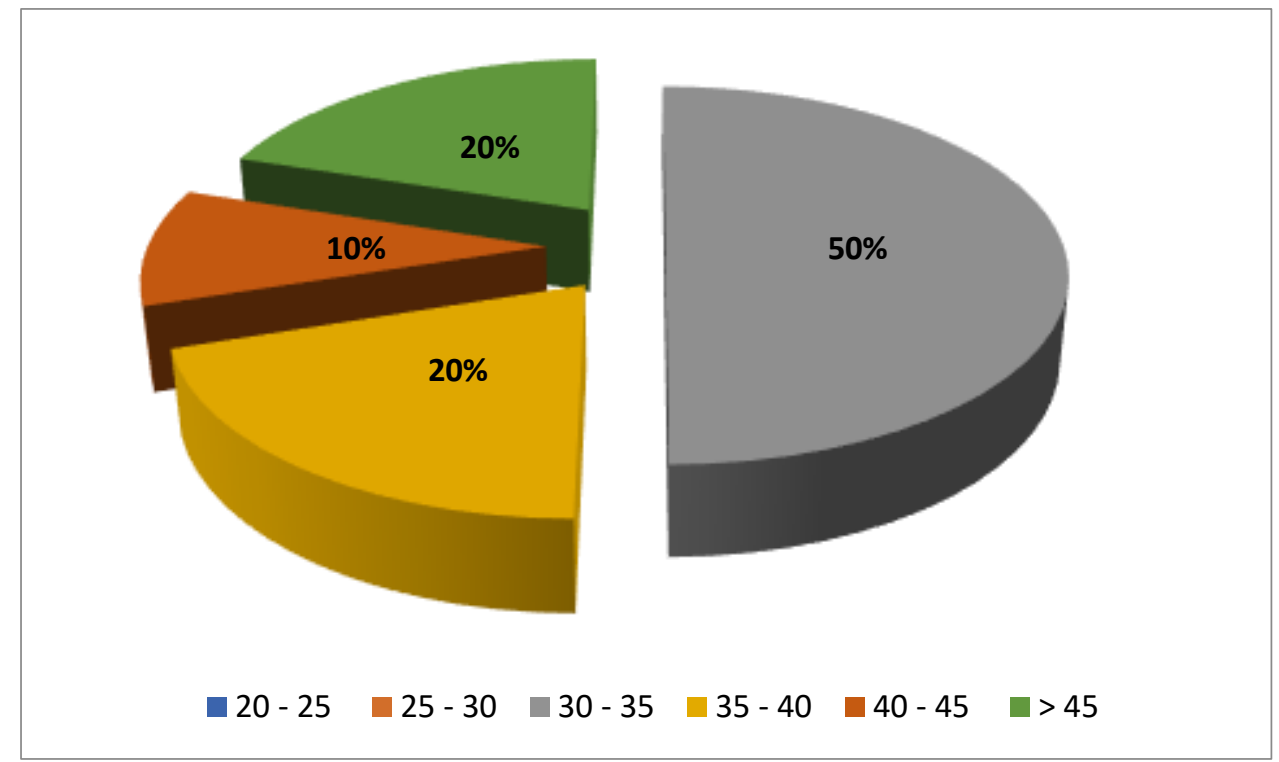

Fonte: Pesquisa de campo. Autor, 24 de março de 2020.

Os dados apresentados no gráfico 1 relevam a grande experiência de vida dos professores investigados, pois estes possuem idades superiores aos 30 anos e possuem experiência na docência de Geografia numa média de 15 anos. Essa larga experiência é bastante positiva, pois estes já possuem uma grande bagagem, mas também pode-se destacar que estes já passaram pelos dissabores da educação nacional.

A maciça maioria dos professores, o equivalente a $90 \%$ dos entrevistados foram graduados em uma instituição de ensino superior particular - O Centro Universitário de Patos, antigamente chamado de Faculdades Integradas de Patos - e apenas 10\% (1) dos entrevistados estudou em uma instituição de ensino pública - A Universidade Federal da Paraíba: UFPB.

Não é nosso objetivo aqui analisar qual instituição é melhor, pois cada uma realiza seu papel de acordo com o que se propõe - a particular dedica-se a formação do professor e a pública, além disso, forma também professor-pesquisador. Mas, uma não anula a outra, pois o bom professor é por natureza um pesquisador. 
Gráfico 2: Nível de escolaridade dos entrevistados

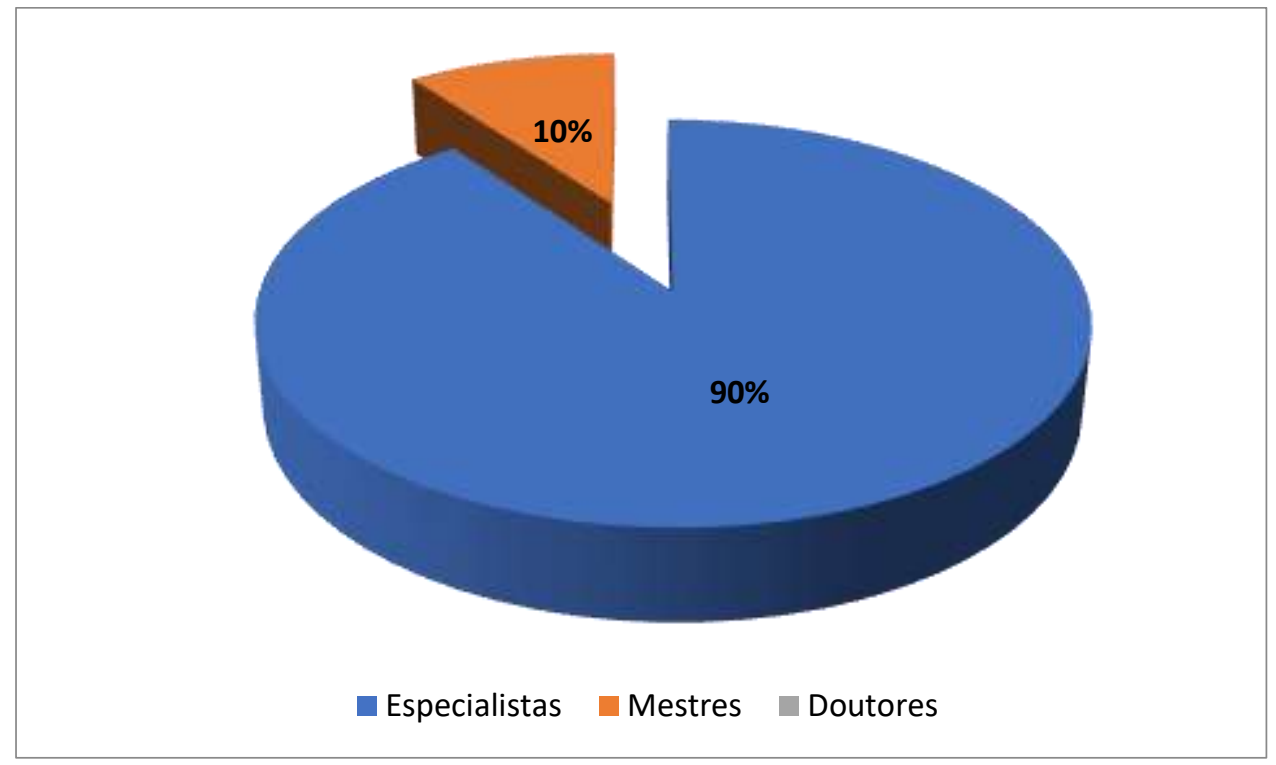

Fonte: Pesquisa de campo. Autor, 24 de março de 2020.

Nota-se que todos os entrevistados são especialistas na área onde atuam ou em áreas afins, mas apesar da vasta experiência na docência apenas $10 \%$ (1) realizou uma pós-graduação no nível de mestrado. Este fator está ligado diretamente com a carência na oferta de cursos de pós-graduação na localidade e também por certo comodismo dos professores de não buscar tal capacitação em outros centros.

Segundo Suertegaray (2003, p. 18) "Dos anos 80 em diante, evidenciou-se uma crescente expansão dos cursos de pós-graduação em Geografia”. No entanto, mesmo em 2020 estes cursos de pós-graduação ainda estão limitados às sedes das capitais dos estados ou de grandes centros. No caso analisado só há pós-graduação em nível de mestrado e doutorado em Geografia na capital paraibana que fica a mais de $300 \mathrm{~km}$ de distância de Patos o que dificulta a participação de sertanejos.

Também buscou-se identificar se estes profissionais participaram de cursos de formação continuada nos últimos cinco anos, pois a docência é uma função que tem que estar constantemente se atualizando. Assim questionou-se se a instituição de ensino onde atuam promove cursos de aperfeiçoamento. Os resultados estão no gráfico a seguir: 
Gráfico 3: A instituição de ensino oferece cursos de formação continuada?

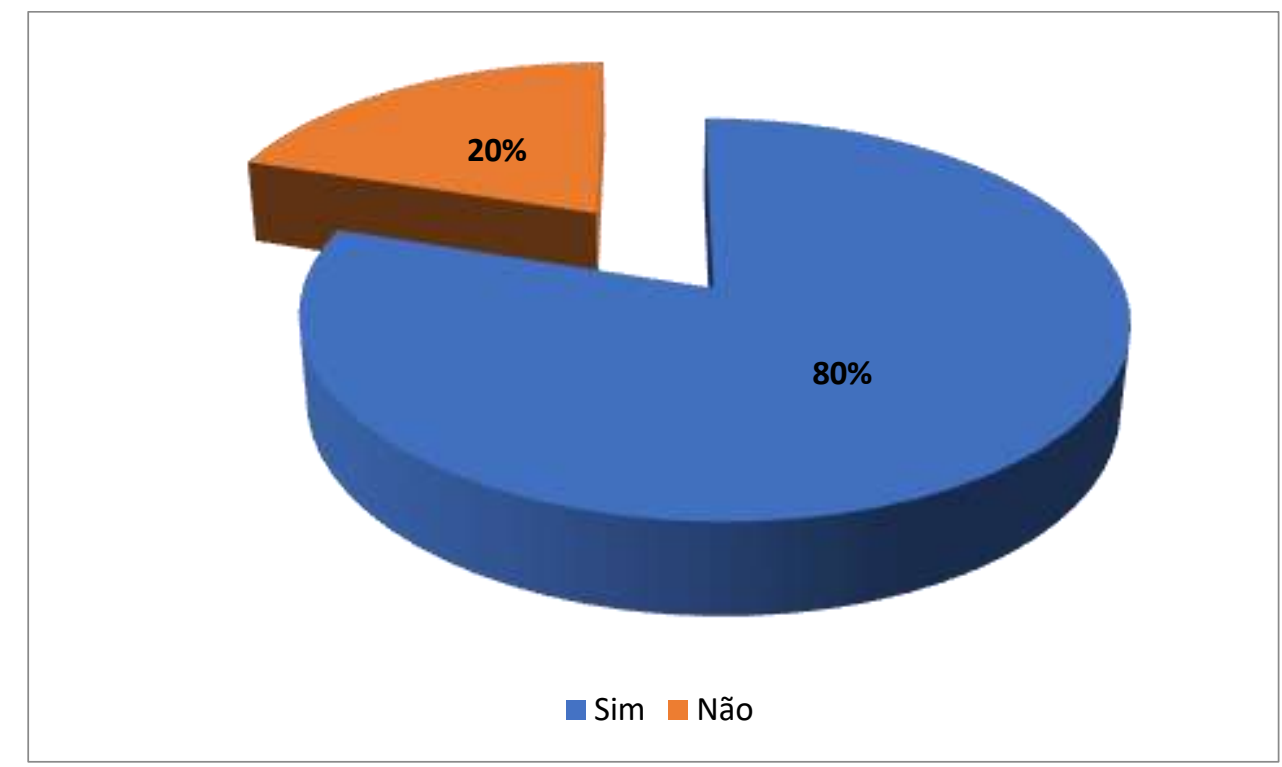

Fonte: Pesquisa de campo. Autor, 24 de março de 2020.

Aos professores, principalmente àqueles que estão exercendo a docência neste ano letivo de 2020 surgem algumas novidades, algumas exigências. Estas, por sua, perpassam não apenas pela sua atualização no tocante aos fatos, acontecimentos e fenômenos que ocorrem na atualidade, mas também, em relação aos conhecimentos curriculares e pedagógicos e às novas tendências educacionais, principalmente sobre as indicações trazidas pela Base Nacional Comum Curricular.

Ao serem questionados sobre a participação em cursos no período de 2015 a 2020 todos os entrevistados responderam que realizaram algum curso de formação continuada e $80 \%$ destes afirmaram que o curso foi oferecido pela instituição de ensino e apenas $20 \%$ disseram que o curso foi realizado por conta própria. Apesar de termos um número de instituições que não promoveu a capacitação dos seus professores nota-se que há um número significativo de escolas promovendo a qualificação dos seus professores.

A formação continuada na concepção de Cavalcanti (2010, p. 172) [...] "exige uma conscientização do professor, um compromisso com o aluno e com o seu desenvolvimento intelectual" [...]. Neste sentido, a formação continuada é uma responsabilidade da instituição de ensino, mas, também e, sobretudo, do professor. 
Nos dias atuais, com a evolução dos meios tecnológicos com os quais a geração atual já tem total posse e domínio, exige da educação uma evolução nos recursos utilizados para planejamento e elaboração das aulas.

Neste sentido, os professores entrevistados foram questionados sobre a disponibilidade de recursos materiais que podem ser utilizados na execução de suas aulas. Estas informações nos parecem, infelizmente, serem bastante fiéis e representam uma larga discrepância entre o que é ofertado na escola particular e o que se dispõe na escola pública.

Gráfico 4: Recursos didáticos disponíveis na escola

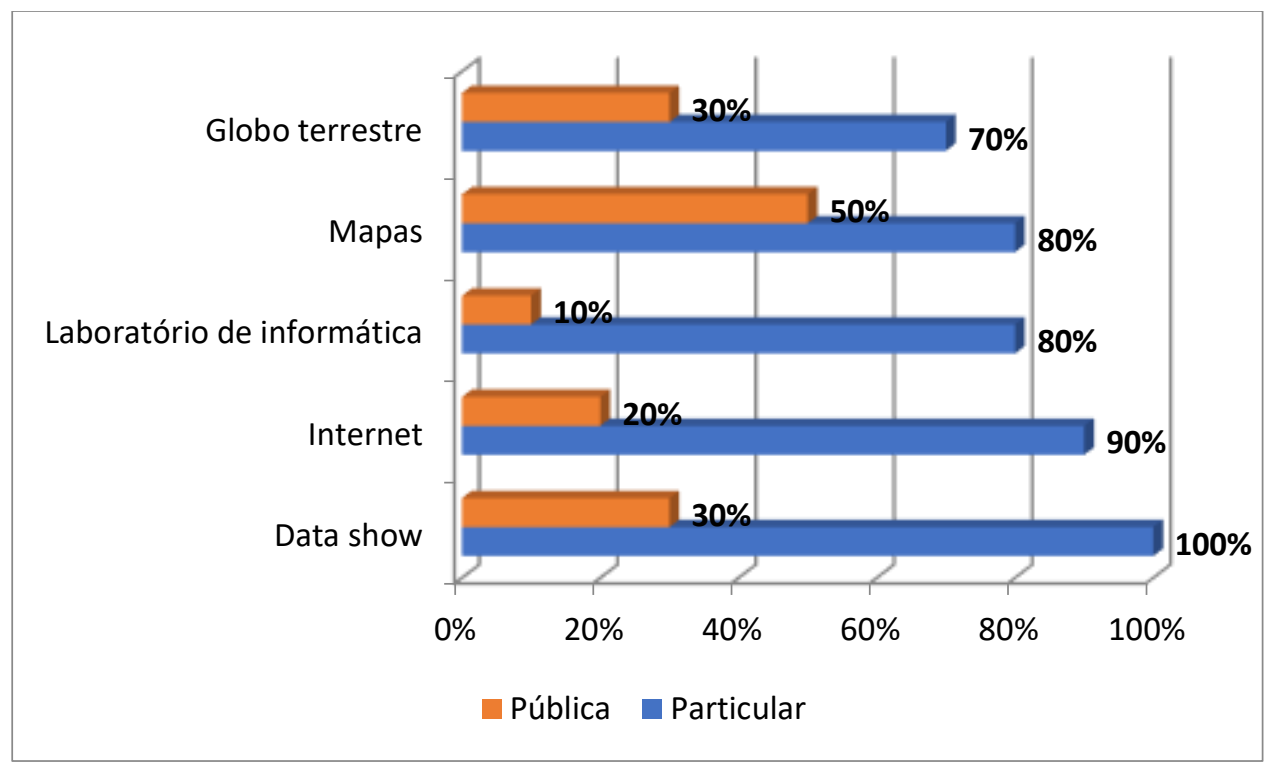

Fonte: Pesquisa de campo. Autor, 24 de março de 2020.

Tais dados nos faz refletir sobre a concepção de Kaercher (2010, p. 17) quando diz: [...] "Que bom seria que a Geografia não estivesse mais presa a tantas medíocres aulas, ainda quase que exclusivamente baseadas em livros didáticos, questionários pobres e exposições burocráticas, mecânicas e conservadoras" [...]. Ao analisar os dados do gráfico 4 evidencia-se uma dura tarefa enfrentada cotidianamente por estes professores para que suas aulas se tornem cada vez mais atrativas e dinâmicas.

Além dos questionamentos realizados de forma objetiva foi questionado aos professores quais outros fatores dificultam o desenvolvimento de suas aulas e afeta de forma direta na aprendizagem dos educandos. Os professores das escolas das escolas particulares responderam: a grande maioria dos professores afirmou não encontrar problemas para execução de suas aulas e outros disseram ter uma carga horária destinada à disciplina reduzida; já os professores das 
escolas públicas alegaram: ausência da família, possível envolvimento dos alunos com drogas, violência, desinteresse e falta de recursos.

\section{CONSIDERAÇÕES FINAIS}

Ao estudar um pouco da educação nacional e como ela se concretiza na prática, nos diferentes lugares, com realidades sociais, econômicas, culturais bastante diferentes evidenciase que ela não deve ser pensada para um público geral e homogêneo, pois as condições, os interesses, os objetivos são muito variados.

Em relação ao município de Patos - PB percebe-se que por se tratar de um município de porte médio (a nível estadual) que a educação pública apresenta algumas dificuldades que perpassam não apenas pelo campo do processo de ensino-aprendizagem, da disponibilidade dos recursos didáticos, ou da formação acadêmica dos professores, mas, sobretudo, pelo descaso ou pela desorganização da instituição família que não acompanha o desenvolvimento educacional dos seus filhos o que reflete em desinteresse e abandono escolar.

Estes problemas interferem diretamente na abordagem de todos os componentes curriculares e de Geografia de modo particular por se tratar de uma ciência ligada à área das ciências humanas onde às questões sociais são discutidas de forma mais efetiva na tentativa de forma um cidadão consciente dos seus direitos e deveres.

Fazendo uma analogia entre as redes de ensino - pública e particular - por meio da aplicação de questionário pôde-se verificar que os professores de Geografia que atuam em ambas apresentam formação acadêmica similar e tempo de docência semelhante, o que nos leva a concluir que o ponto que diferencia e interfere na qualidade do ensino está ligado diretamente às questões de estrutura social, familiar e a disponibilidade dos recursos didáticos nas escolas.

Portanto, fica um questionamento para ser investigado posteriormente: os recursos financeiros disponíveis para as escolas públicas e particulares são os mesmos? Por que a rede particular dispõe de maiores recursos? Assim, entenderemos a ausência destes recursos em muitas instituições de ensino do município e porque não dizer do país todo. 


\section{REFERÊNCIAS}

ASSIS, Maria Cristina. Metodologia do Trabalho Científico. São Paulo, 2009.

BRASIL. LDB - Leis de Diretrizes e Bases da educação nacional. Lei no 9.394. de 20 de dezembro de 1996. 14. ed. Brasília: Câmara dos Deputados, Edições Câmara, 2017.

BRASIL. Secretaria de Educação Fundamental. Parâmetros curriculares nacionais: introdução aos parâmetros curriculares nacionais / Secretaria de Educação Fundamental. Brasília: MEC/SEF, 1997.

BRASIL. Base Nacional Comum Curricular (BNCC). Educação é a Base. Brasília, MEC/CONSED/UNDIME, 2017. Disponível em: http://basenacionalcomum.mec.gov.br/images/BNCC_EI_EF_110518_versaofinal_site.pdf >. Acesso em: 26 mar.2017.

CALLAI, Helena Copetti. Estudar o lugar para compreender o mundo. In: CASTROGIOVANNI, Antonio Carlos (Org.) Ensino de geografia: práticas e textualizações no cotidiano. $7^{\mathrm{a}}$ ed. Porto Alegre: Mediação, 2009.

CAVALCANTI, Lana de Souza. Geografia, escola e construção de conhecimentos. 10 ed. São Paulo: Papirus editora, 2010.

IBGE. INSTITUTO BRASILEIRO DE GEOGRAFIA E ESTATÍSTICA. Divisão regional do Brasil. Rio de Janeiro: RJ. Disponível em: https://biblioteca.ibge.gov.br/index.php/biblioteca-catalogo?view=detalhes\&id=2100600 Aceso em: 26 mar.2017.

KAERCHER, Nestor André. Desafios e utopias no ensino de Geografia. 3. ed. Santa Cruz do Sul: EDUNISC, 2010. 
PORTAL QEDU. Número de escolas em Patos. Disponível em: <https://www.qedu.org.br/busca/115-paraiba/4043-campina-grande>. Acesso em 26 mar. 2020.

SUERTEGARAY, Dirce Maria Antunes. A expansão da pós-graduação em Geografia e a ANPEGE. Revista da ANPEGE. Rio Grande do Sul. v. 1, n. 01 (2003). 